\title{
Dynamics of the Professional Orientation of the Students in the Specialty of Pre-School and Primary School Education
}

\author{
Maria Teneva
}

\begin{abstract}
The article presents the problem of the vocational orientation of students who are mastering the professions of pre-school and primary-school teachers at the Faculty of Education at Trakia University.

The subject of the study is the professional orientation of students in the specialty "Pre-school and primaryschool education".

The object of the study is the dynamics of their career orientation from the first to the last year of their studies at the university.

The aim is to establish the level of professional orientation of students mastering the teaching profession.

The following research methods were used for the implementation of the so set aim: test, content analysis, pertinent analysis, longitudinal study.

Presented are the results of the author's study, tracking the dynamics of the professional orientation of the students during the first and the last year of their studies in the faculty.

The results indicate that the professional choice of future pedagogues is conducted in accordance with a process of realization of their professional self-identification. The young people who study Pre-school and Primary School Education choose their future profession on the basis of their high level of professional orientation. A supportive pedagogical environment in the course of their training helps to raise the level of their professional orientation.
\end{abstract}

Key words: Training, Career Guidance, Professional Choice

Language: English

Date of Submission: 2018-03-20

Date of Acceptance: 2018-04-20

Date of Publication: 2018-04-30

ISSN: 2321-1091

Volume: 12 Issue: 01

Journal: JOURNAL OF SOCIAL SCIENCE RESEARCH

Website: https://cirworld.com

This work is licensed under a Creative Commons Attribution 4.0 International License 


\section{INTRODUCTION:}

Throughout all his or her life, each person is free to make a number of choices. Some of them are of less significance, others are of greater significance and have an impact on the person's overall existence. One of the most important choices for the prosperity of the person is the choice of profession. The factors influencing the professional choice could be sought in several directions. Some of them relate to the characteristics of the person, to his or her inner attitudes and inclinations. Others closely correspond to the peculiarities of the environment and the social relationships created within it. A large number of researchers devote their scientific research to differentiating and analyzing various factors that provoke the professional choice made by the person. Regardless of the fact to which factors they attach greater importance, they all unite around the idea of the personal freedom in choosing a profession and the possibility that this choice can be made repeatedly.

\section{DISCUSSION:}

One author popularizing his ideas about the free choice of profession is A.P. Solovyev (Solovyev, 1979). He presents a model for choosing a profession, which is characterized by three key factors - personal abilities, interests and labor market. Among these, several intersections can be observed. The author emphasizes the importance of three key sections influencing the choice of profession, namely: matching the interests and capabilities of the person, synchronizing personal and public interests and the possibility of free choice of profession (in line with the abilities of the person) based on the possibility of realization on the labor market. A.P. Solovyov does not attempt to present a "recipe" for successful professional choices but to defend the idea that the person has the possibility of a professional choice and should take advantage of it (Solovyev, 2013). Another author's model for the selection of a profession is represented by E.A. Klimov. His model, as well as the model of A.P. Solovyov, also consists of three components. It is characterized by an outlined relationship (intersection) between the components "I want - I can - I must" (Klimov, 1987). When presenting his model, E.A. Klimov examines the triangular dependence of the components of desires (I want) - abilities (I can) preferences/beliefs (I must). The interections between the three components of the model arise from the peculiarities of the formation of the inner structure of the personality and the influence of the social factors of the environment. A similar idea in the Bulgarian scientific literature is presented by $\mathrm{D}$. Vassilev and $\mathrm{Y}$. Merdjanov. The two authors consider that the choice of profession should be done according to the "interests of the personality (defining its preferences and ambitions in the sector of what is desired); the abilities and qualities of the person (defining its features as opportunities and limitations in the sector of what is available) the characteristics of the labor market and the profession - the objective context of the choice"(Vassilev, Merdjanova, 2003). They argue that the decision to choose a profession must be taken on the basis of the three main groups of circumstances. Since it is difficult to meet the requirements of all three sectors, professional choices would have to be preceded by skillful professional guidance.

Significant factors for professional choices can be pointed out to be the needs of the person, his or her abilities and interests (Teneva, 2017). These key factors are in triadic dependence, they are projected on the motivation of the person and model its behavior.

The opinion that the choice of profession is not a purely personal act is shared by I. Petkova. She points out that the professional choice is "bound, influenced, socially predisposed by the development of society, the economic situation and priorities in the country, the socio-economic status of the profession itself, its prestige, the opportunity for career development" (Petkova, 2012). The author shares the understanding that choosing a profession is not an instant act, but a result of a long and gradual process through which the person passes.

I.S. Kong finds the relationship between professional orientation and the person's life plan. The author points out that, in a narrow sense, the plan of life includes the conscious identifying of the way for the person to follow, differentiating between the objective and subjective resources that are needed in order to follow this path, determining the means of achieving the end result (Kon, 1979). 
Such a correlation is also revealed by P.A. Shavir, who points out that the process of professional selfdetermination involves not only the person's orientation in choosing a profession but also internal psychological grounds for that choice (Shavir, 1981).

V.I. Perevedcev points out that the personal choice of profession is based on its social positions and professional orientation (Perevedcev, 1980).

P. Alexandrov reveals important interrelations between professional self-determination and the social maturity, social prestige and professional awareness of the person (Alexandrov, 1987).

A.M. Kucharchuk and A.B. Centsiper believe that professional self-determination is the result of an analysis of the internal resources and abilities of the individual, related to the requirements of the professions. The authors consider professional choices to be a consequence of the professional self-determination of the personality (Kucharchuk, Centsiper, 1976).

The quoted opinions of researchers in the field of professional choice are united around the idea that it is influenced by factors of different nature (some of them are rooted in the personality itself, others in the specifics of the social relations which he or she enters). They assume the idea that in their lifespan people go through a complicated path of professional self-determination, as a result of which they make their professional choices in line with the concept of personal freedom and autonomy. The fact that the professional choice, according to a large number of authors, is characterized by certain dynamics, reveals new horizons in front of the person. The person is responsible for the consequences of his or her choice, but the fact should not be diminished that it is also affected by external factors that are sometimes difficult or even impossible to predict in the projection of time. When a person is struggling to make this crucial choice for him or herself, he or she may be guided by a career guidance consultant. When in the course of their professional development people find that their occupation does not satisfy their needs, this should not lead to despair, lack of self confidence and self-isolation. In this case, it is necessary for the person to walk the difficult path to self-knowledge and to carry out a corrective process. During the remedial process it is necessary to reassess one's professional self-determination. It is necessary for the person to highlight his or her strengths and personal qualities, to hierarchize his or her personal priorities, to synchronize his or her interests and abilities, to try to bring his or her personal interests closer to the social ones, to take into account the realities of the labor market and, on this basis, make new professional choices - if necessary, even in a completely different from the current field. Professional choice should be analyzed according to the understanding of its stage-bystage development, dynamism and multiplicity.

Successful professional choice has a positive projection on the feeling of job satisfaction, it creates a sense of acceptance from the social environment and eases the process of self-acceptance. It provokes a desire for career development, for exerting more efforts in order to raise professional competence and generates a conscious striving for personal self-improvement. In the last decade all these issues called for the need to work purposefully towards the so-called "career education". According to Y. Merdjanova, career education is structured in a meaningful way as a set of information, consultancy and / or training activities organized at regional, national and international level, designed to form career management skills on two levels - selfknowledge and self-realization, and in three aspects - towards the personality, the labor market and the professional organization"(Merdjanova, 2012). The author examines the causal relationship and interdependence between career guidance, career education and career management.

\section{RESEARCH AND METHODOLOGY:}

When the person makes his or her professional choice, they present an unequivocal request to society for his or her social maturity and readiness for personal realization in social life and the labor market. This provoked our research focus on achieving the following goal: 
Purpose of the study: To establish the level of professional orientation of young people who choose to dedicate themselves to the teaching profession.

Research tasks: To elaborate the theoretical grounds of the problem of the specifics of professional choice;

to determine to what extent students are personally responsible and socially mature in making their professional choices;

to reveal the dynamics of the professional orientation of the students from the pedagogical specialties from the first to the last year of their studies at the university.

Research instruments: a standardized test called "Professional Guidance for Students", developed by Tatiana Dubovitskaya (Dubovitskaya, 2004), was used.

Methods of the survey: test, content analysis, pertinent analysis, longevity study.

Contingent of the study: 56 students from the specialty Pre-school and Primary School Pedagogy who are trained at the Faculty of Education at Trakia University, Stara Zagora, of which 28 students are in the first year and 28 are in the fourth year of their course of that specialty. The age distribution of the students covered is the following:

For the students of the 1st year: 19 - 20 years of age: $76.92 \% ; 21-24: 3.85 \% ; 25-30: 5.77 \% ; 31-35: 7.69 \%$; over 35: $5.77 \%$.

For the students of 4th year: 23 - 24 years of age: 76.92\%; 25-30: 3.85\%; 31-35: 11.54\%; over 35: 7.69\%.

From the statistical data recording the respondents' age, it can be concluded that the largest share is held by students who continue their education at the higher school immediately after completing the upper secondary education stage. Approximately $77 \%$ of the freshmen surveyed are aged $19-20$. This share is retained with the graduating bachelor students who are 23-24 years old at the end of their studies.

The test gives the respondents the opportunity to answer 20 questions with "yes" or "no" on the basis of which a test ranking is formed. According to it, students are differentiated into three groups - of high, medium and low level of professional orientation.

\section{RESULTS:}

The students in Pre-school and Primary School Education ( $1^{\text {st }}$ year), covered by the study, are differentiated into two groups. The data indicate that $71.43 \%$ of them choose a future profession based on a high level of vocational guidance. For $28.57 \%$ of the freshmen student's professional choices were made on the basis of an average level of vocational orientaion. There are no reported cases where the first-year students in the specialization program are characterized by a low level of professional orientation, under which professional choices have been made. For $92.86 \%$ of the students in the specialization program Pre-school and Primaryschool Education there is a high level of professional orientation, on the basis of which they have made their professional choice. For $7.14 \%$ of the students an average level of career orientation is characteristic on which their professional choices are based. There are no cases where the fourth-year students in the specialization program have a low level of professional orientation in the realization of their professional choices. The data obtained confirm the view that the choice of profession is characterized by dynamism. Vocational guidance for students from the first to the fourth year of their studies at the university undergoes a significant change in the direction of increasing the number of students with a high level of vocational guidance. In the case of the students in the specialization program (1st year), there is gradual dynamics of the professional orientation, on the basis of which the professional choice was made (the values increase by about $40 \%$ ). Vocational orientation, defining the specifics of the professional choice of the students in the specialization program Pre- 
school and Primary-school Education (4th year), is characterized by a jump in dynamics (the values increase by about $85 \%)$. Vocational orientation rates for the students from the $4^{\text {th }}$ year course start at a lower level $(7.14 \%)$ and reach almost the highest possible maximum (92.86\%). In both target groups there is no tendency for the professional choices of the students to be based on a low level of vocational orientation, the students enrolled in the study received a test mark between 0 and 4 points. We find a difference in the two target groups with regard to the average level of vocational orientation found at the base of the professional choice. The share of students in the specialty Pre-school and Primary-school Education in their the first year ( $1^{\text {st }}$ course), who are characterized by an average level of vocational orientation, amounts to $28,57 \%$, while the share of the students in the same specialty (Pre-school and Primary-school Education (4th year) with an average level of vocational orientation amounts to $7,14 \%$. We register a downward trend in the respective first-to-fourth year by $21.43 \%$. For the differentiated $21.43 \%$ of students it is characteristic that that they have added a new meaning to their professional choices during the period of their 4-year course. First-year students in the specialty Pre-school and Primary-school Education who have an average level of professional orientation are hesitant in their decision, if given a new opportunity to choose to study in the same specialty. They acknowledge that they have been influenced for their choice by occasional circumstances, and that the decision for their training has been dictated by their desire to obtain a higher education diploma, not so much by their interest in the profession they ate mastering. They still do not foresee very good options for themselves in their future profession. They are not confident that in the future exactly this profession will cooperate to the utmost extent for their self-expression. They do not think in the direction of professional self-development and selfrealization. The specificity of these responses convinced us that choosing a profession for these students is not synchronized with their needs. The professional choice for the first-year students in the specialty Pre-school and Primary-school Education, which is characterized by an average level of vocational orientation, is not balanced also in terms of their abilities and interests. The hobbies and leisure activities of this group of students are not yet related to their occupation. They do not read on their own initiative additional literature that is related to their future profession. They do not currently work and do not want to work in the profession they have mastered; they see very few nice things for themselves in this profession. They respond affirmatively that there are many other professions that they like more than the one they are currently mastering in the university. The period of study at the higher school affects in a positive way a part of these students. We noted that their share in the first year of training was $28.57 \%$, but the four years of their training lead to a decline of $21.43 \%$, and in the last year of their training an average level of vocational orientation was found with only $7,14 \%$ of the students in the specialization program Pre-school and Primary-school Education. One (3.57\% of the cases) failed in the whole period of four years, during which she mastered the profession of "pre-school and primary-school teacher", to transform her motivation to choose a profession and specialty in a positive direction. This student continued from the first to the last year of her studies to claim that she was being forced to study in the present faculty under certain circumstances and not by her own desire to master the profession concerned. She still continues to think that there are other professions that are much nicer than the one she is currently mastering. This student is convinced that it is unlikely that the profession she is mastering at the moment and which she will have to work later on will contribute to her moral satisfaction. Rather, she is convinced that she will try to take up a new profession which she will devote herself to in the future. Because the current survey does not imply the free design of the answers, we cannot accurately determine the circumstances that led the students to this faculty and specialty in the first place. We can make assumptions about this in several directions: parental ambitions, motivation influenced by friendly choices, aspirations to obtain a higher education diploma, no matter in what specialty, a desire for carefree student life and postponement of work commitments for several years, an opportunity to get training which the city where the young person lives provides, an exam mark at the entrance exams that has ranked the candidate student only in this specialty, and many more options. The same share of fourth-year students - one student (3.57\%) - also fails to transfer into higher than average levels her career orientation, but the reasons given for this are different from those outlined in the previous case. This student states that she studies at the faculty because of her desire to master this profession, and if she was offered a new opportunity to study, she would again choose the same specialty she is currently studying. Here we reveal the tendency of a clear mismatch between professional choices and the interests and abilities of the person. We register responses according to which hobbies and leisure activities of the student are not related to the future profession, he or she does not read 
on their own initiative additional literature related to the future profession, do not foresee after their graduation to build upon his or her knowledge, skills and competences in the acquired profession in order to be able to exercise it more effectively.

The students in the specialty Pre-school and Primary-school Education ( $4^{\text {th }}$ year), who are characterized by an average level of vocational orientation, are unified in their answers in several directions. They are united around the view that it is unlikely that their occupation and work will bring them moral satisfaction in the future. This response correlates with the statement we have expressed about the discrepancy between professional choices and the needs of the person. Students in this group indicate that they do not work, do not want to find a job, or even that they would take steps to stop working in the occupation they have mastered.

What is worrying is the fact that for four years the faculty is educating students for whom the educational environment is not able to influence positively the level of their professional choices. They are characterized by an average level of vocational orientation from the first to the fourth year of their studies. Despite the conditions created in the faculty (acquaintance with the work of prominent pedagogues in the practice, formation of theoretical and practical and applied pedagogical competences through the auditorium and outof-the-auditorium field activities, attempts to draw the students to the profession of "pre-school and primaryschool teacher" by conducting hours of observation of lessons, student placements, current and pre-graduate practice, inclusion in research projects in research teams, inclusion in the Erasmus + International Student Transfer Program, opportunities to participate in scientific forums in Bulgaria and abroad, conducting joint initiatives with children from kindergartens and primary school pupils, etc.), they do not increase their level of professional orientation. The positive issue in this tendency could only be found in the fact that the share of this group of students in the specialty Pre-school and Primary-school Education (4th year) is small and amounts to only $7.14 \%$.

Analyzing the dynamics of the professional choice of the students in the specialty of the Pre-school and Primary-school Education ( $1^{\text {st }}$ - 4th year), it is necessary to emphasize the tendency for an increase of the share of students with a high level of vocational orientation from the 1st to the 4 th year of their training. For the freshmen, this share amounts to $71.43 \%$, while for fourth-year students it is $92.86 \%$. In this case, we recorded an increase of $21.43 \%$. As can be seen from the data obtained, the specialty of Pre-school and Primary-school Education is attractive to young people and although on entering the university they still do not know in detail the specifics of the profession they are about to master, more than $71 \%$ of those who choose this specialty are characterized by a high level of professional orientation. Through the research data with the students of the specialty of Pre-school and Primary-school Education (4th year), we establish a positive trend for the activities of the Faculty of Education at Trakia University. This trend is in the direction of increasing the share of students with a high level of vocational orientation from the first to the last year of their education in the higher school. This is a good attestation to the supportive environment that the faculty provides for its students. As we found from the research data, in the fourth year of the students' education this proportion exceeds $92 \%$. For students with a high level of vocational orientation it is characteristic that they are trained at the Faculty of Education at Trakia University, led by their desire to master the professions "pre-school teacher" and "primary-school teacher". They are convinced that if they were given a new opportunity they would again choose to study at the same faculty and the same specialty they are currently studying. They affirm that their desire to master this profession and exercise it is sustainable and well-grounded. For them, dominating is the desire for professional realization rather than the pursuit of a higher education diploma as an end in itself. They find many good things for themselves in their future profession and they are confident that it will give them the best opportunity to express themselves. This group of students plan after graduation to take measures to continue their education and to build up their professional knowledge, skills and competencies in order to make their professional realization more effective. From the specifics of the answers received, we establish the tendency according to which the students with a high degree of professional orientation make a professional choice that is in line with their needs. Professional choices based on volunteering and conviction, plus 
professional realization, accompanied by plans for self-development and career development, would meet the needs of the person from the lowest to the highest hierarchical level.

The professional choice of the students in the specialty of the Pre-school and Primary-school Education ( $11^{\text {st }}$ to $4^{\text {th }}$ year), in which we establish a high level of vocational orientation, choose their profession in accordance with their interests and abilities. This trend can be demonstrated by the specifics of the answers given by the students covered by the study, based on the test "Professional orientation of the students". For students with a high level of professional orientation their hobbies and leisure activities are related to the future profession. They, on their own initiative, read extra literature which is related to their future profession. Even if this proves difficult, after graduation they will try to find and start work in the field of the mastered profession. They do not plan, after graduating, to make a new professional choice in another field and specialty. This group of students is convinced that it is precisely the profession they are currently occupying that will allow them in the future to express themselves and their abilities in the best possible way.

\section{CONCLUSSIONS:}

The results of the research performed with students from the specialization of Pre-school and Primary-school Education (1st $-4^{\text {th }}$ year) in terms of their professional choice, obtained through the test "Professional orientation of the students" provide the basis to draw conclusions in several directions:

The professional choice of the students from the specialization of Pre-school and Primary-school Education (1st -4 th year) is the result of the previous process of professional self-determination, whose component is professional orientation.

The professional choice of the students in the specialization course of Pre-school and Primary-school Education (4th year) is based on a high and average level of professional orientation, which greatly affects its conviction and sustainability.

The supporting educational environment in the faculty has a positive impact on the level of conviction in the correctness of the students' professional choices.

The professional choice of the students of the specialization of the Pre-school and Primary-school Education (1st -4 th year) is characterized by dynamism. From the first to the fourth year of the students' education the proportion is increased of those whose professional choices are made in accordance with the high level of vocational orientation and that of those whose professional choices are based on an average level of vocational orientation is decreased.

\section{LITERATURE:}

1. Alexandrov, P. (1987). Professional self-defining of the person. Sofia. p. 32.

2. Vasilev, D., Merdjanova, Y. (2003). Theory and methodology of professional oreintation. Publ." St Kliment Ohridski". Sofia. p. 20.

3. Dubovitskaya, T. D. (2004). Diagnostics of the level of the professional orientation of the students. Psychological science and education, № 2. Publ. "Science and Education". Moscow. p. $82-86$.

4. Klimov, E. A. (1987). Foundations of production. Choice of a profession, publ. "Prosveta", Moscow

5. Kon, C. (1979). Psychology of adolescence. Moscow. p. 146. 
6. Kuharchuk, A. M, Tsentsiper, A. B. (1976). Professional self-defining of the students, Minsk. p. 7

7. Merdjanova, Y. (2012). European career education in Bulgarian conditions. Pedagogy, № 1. Sofia. p. 79.

8. Perevedtsev, V. I. (1989). The man chooses a profession. Moscow

9. Petkova, I. (2012). Preparation and qualification of the Bulgarian teacher, Publ." St Kliment Ohridski". Sofia. p. 87.

10. Solovyev, A. (1979). Professional orientation in the socialist society. Moscow. pp. $70-71$.

11. Solovyev, A. (2013). Choice of a profession. Publ. "Eksmo". Moscow

12. Teneva, M. (2017). Who is a good teacher? Publ. Trakia University, Stara Zagora. pp. 9-10.

13. Shavir, P. A. (1981). Psychology of the professional orientation in adolescence. Moscow. pp. 7- 19. 